\title{
Effects of metal ions on the structure and activity of a human anti-cyclin D1 single-chain variable fragment AD5
}

\author{
NING YANG $^{1 *}$, NANNAN YAO $^{1 *}$, XIANGZHI LIAO ${ }^{1}$, XIAONA XIE $^{2}$, \\ YAN WU $^{1}$, CHUANXI FAN ${ }^{1}$, JIALIANG ZHAO ${ }^{1}$ and GUIYING LI ${ }^{1}$ \\ ${ }^{1}$ Key Laboratory for Molecular Enzymology and Engineering of The Ministry of Education, \\ School of Life Sciences, Jilin University, Changchun, Jilin 130012; ${ }^{2}$ Department of Endocrinology, \\ The First Hospital of Jilin University, Changchun, Jilin 130021, P.R. China
}

Received April 20, 2016; Accepted April 7, 2017

DOI: $10.3892 / \mathrm{mmr} .2017 .6756$

\begin{abstract}
Cyclin D1 has become a potential target for anti-tumor therapy. Recently, a novel human anti-cyclin D1 single-chain variable fragment (AD5) was identified, which demonstrated specific binding activity to cyclin D1 and exhibited anti-tumor effects. However, the detailed characteristics of AD5 remain unclear. In the present study, the structure and activity of AD5 in the presence of copper II $\left(\mathrm{Cu}^{2+}\right)$ or iron III $\left(\mathrm{Fe}^{3+}\right)$ metal ions was investigated by fluorescence spectroscopy, synchronous fluorescence and enzyme-linked immunosorbent assay. $\mathrm{Cu}^{2+}$ and $\mathrm{Fe}^{3+}$ were able to bind to AD5 and quench the fluorescence intensity of AD5 primarily by static quenching, which slightly altered the conformation of AD5 at temperatures of 293, 298 and $303 \mathrm{~K}$; however, these temperatures demonstrated different effects on the activity of AD5. These results may be of value for the clinical application of anti-cyclin D1 single chain antibodies in the future.
\end{abstract}

\section{Introduction}

As an important regulator of cell cycle, cyclin D1 is frequently associated with tumor occurrence and development $(1,2)$. The gene encoding cyclin D1 is an oncogene that represents the second most frequently amplified locus in a diverse range of human cancers (3). Overexpression of the cyclin D1 protein has been described in a variety of human cancers $(1,4-6)$. Previous studies have demonstrated that the expression of cyclin D1 is an important indicator of therapeutic efficacy

Correspondence to: Professor Guiying Li, Key Laboratory for Molecular Enzymology and Engineering of The Ministry of Education, School of Life Sciences, Jilin University, 2699 Qianjin Street, Changchun, Jilin 130012, P.R. China

E-mail: ligy@jlu.edu.cn

*Contributed equally

Key words: single-chain fragment variable, cyclin D1, metal ions, activity, spectroscopy for a number of therapeutic agents, including all-trans retinoic acid, which is closely associated with prognosis (7). Due to its frequent deregulation and role in cancer development, cyclin D1 has become a potential target for anti-tumor therapy.

Antibodies have become powerful therapeutic and diagnostic tools, as they bind target antigens with a high degree of specificity and affinity. An antibody in a single-chain fragment variable ( $\mathrm{scFv}$ ) format is constructed by combining the heavy and light chain variable region via a flexible linker peptide. It has a variety of applications in biotechnology and clinical medicine, particularly in the field of oncology, due to its specific binding affinity to target antigens, its small size and ease of engineering (8-12). In a previous study, a novel human scFv antibody (AD5) was prepared, which demonstrated specific binding affinity to cyclin D1 (13). Intracellular AD5 was observed to significantly inhibit tumor cell growth and proliferation, which provided a novel potential tool for targeting cyclin D1 for the treatment of cancer $(14,15)$. However, the mechanism of action and biological characteristics of AD5 remain unclear.

Metal ions in the blood and aqueous solution may affect protein interactions, as metal ions serve a role in protein folding, assembly, stability, conformation and activity $(16,17)$. Trisler et al (18) designed an antibody that forms an irreversible complex with a protein antigen in a metal-dependent reaction. Such irreversibly binding antibodies may facilitate the development of next generation reactive antibody therapeutics and diagnostics. Iverson et al (19) constructed a catalytic metalloantibody (QM212) with a coordinate site for metals in the antigen-binding pocket. They utilized fluorescence spectroscopy to clarify the binding affinity between the antibody and different metal ions. Copper II $\left(\mathrm{Cu}^{2+}\right)$ and iron III $\left(\mathrm{Fe}^{3+}\right)$ are important trace elements in the human body, and affect the structure and function of a variety of proteins (20). Therefore, to improve the use of these antibodies in a clinical setting, it is imperative to investigate the effects of metal ions on the structure and activity of antibodies.

In the present study, the structure and activity of AD5 in the presence of $\mathrm{Cu}^{2+}$ or $\mathrm{Fe}^{3+}$ was investigated by fluorescence spectroscopy and synchronous fluorescence. The quenching constants were obtained at various temperatures. The number of binding sites for the metal ions was determined, as were 
the binding constants and the effect of different conditions. In addition, the effects of $\mathrm{Cu}^{2+}$ and $\mathrm{Fe}^{3+}$ on the biological activity of AD5 were investigated using enzyme-linked immunosorbent assay analysis (ELISA). The results verified the biochemical and biophysical characteristics of AD5, and supported the use of an anti-cyclin D1 single chain antibody in future clinical applications.

\section{Materials and methods}

Materials. AD5 and cyclin D1 were purified as previously described $(13,21)$. A spectroscopic sample of AD5 was prepared in phosphate-buffered solution (PBS) at $\mathrm{pH}$ 7.4. The concentration of purified AD5 and cyclin D1 was determined using a Bradford assay (Sangon Biotech Co., Ltd., Shanghai, China), according to the manufacturer's protocol. The anti-V5-tag antibody (cat. no. M1008-2) was purchased from Hangzhou HuaAn Biotechnology Co., Ltd. (Hangzhou, China). Horseradish peroxidase (HRP)-conjugated goat anti-mouse immunoglobulin G (IgG) (cat. no. SA00001-1) was purchased from the ProteinTech Group, Inc. (Chicago, IL, USA). Bovine serum albumin (BSA) and o-phenylenediamine (OPD) were purchased from Sigma-Aldrich; Merck KGaA (Darmstadt, Germany). $\mathrm{CuCl}_{2}$ and $\mathrm{FeCl}_{3}$ were purchased from Beijing Chemical Works (Beijing, China). All other chemicals were of analytical grade.

Apparatus. Fluorescence and synchronous fluorescence measurements were performed on an RF-5301PC Spectrofluorophotometer (Shimadzu Corporation, Kyoto, Japan) equipped with $1.0 \mathrm{~cm}$ quartz cells. Data were analyzed using Origin software (version 8.0; OriginLab Corporation, Northampton, MA, USA).

Measurement of fluorescence spectra. The concentration of AD5 was maintained at a constant level $\left(2 \times 10^{-6} \mathrm{M}\right)$, whereas the concentration of the metal ions in solution $\left(\mathrm{CuCl}_{2}\right.$ and $\left.\mathrm{FeCl}_{3}\right)$ was varied $\left(0.00,0.33,0.67,1.00,1.33\right.$ and $\left.1.67 \times 10^{-3} \mathrm{M}\right)$ by adding $0,2,4,6,8$ and $10 \mu \mathrm{CuCl}_{2}$ or $\mathrm{FeCl}_{3}(0.1 \mathrm{mM})$ to $600 \mu \mathrm{l}$ PBS. In each fluorescence spectrum test, a fixed concentration of AD5 and a series of solutions were mixed in a $1 \mathrm{ml}$ quartz cell, and incubated for $10 \mathrm{~min}$ at 293, 298 and $303 \mathrm{~K}$. Fluorescence quenching spectra were recorded with emission wavelengths that ranged from 290 to $500 \mathrm{~nm}$, and an excitation wavelength of $280 \mathrm{~nm}$. The excitation and emission slits were set at $5 \mathrm{~nm}$. The absorbance of the system was not high enough to consider inner filter effects, which are caused by the absorption of excitation and emission radiation. Therefore, inner filter effect calculations were not included in the fluorescence studies.

Measurement of synchronous fluorescence. Synchronous fluorescence spectra of AD5 were obtained by simultaneously scanning the excitation and emission spectra. The wavelength intervals $(\Delta \lambda)$ between the emission and excitation wavelengths were individually fixed at 15 and $60 \mathrm{~nm}$, at which the spectrum only demonstrated the spectroscopic behavior of Tyr and Trp residues in AD5, respectively. The concentration of the metal ions and AD5 were the same as the steady-state fluorescence measurement.
Formulas. The Stern-Volmer quenching constant $\left(K_{\mathrm{sv}}\right)$ and the bimolecular quenching rate constant $\left(K_{\mathrm{q}}\right)$ were calculated according to the following Stern-Volmer equation: $F_{0} / F=1+K_{\mathrm{sv}}[\mathrm{Q}]=1+K_{\mathrm{q}} \tau_{0}[\mathrm{Q}](22)$, where [Q] is the quencher concentration, $K_{\mathrm{sv}}$ is the Stern-Volmer quenching constant, $K_{\mathrm{q}}$ is the bimolecular quenching rate constant and $\tau 0$ is the lifetime of the fluorophore in the absence of quencher, which is of the order of $10^{-8} \mathrm{~s}$. For the static quenching, the binding constant and number of binding sites were calculated according to the following equation (23): $\log \left[\left(F_{0}-F\right) / F\right]=\log K_{\mathrm{b}}+$ nlog [Q], where $\mathrm{n}$ is the number of binding sites for one AD5 molecule, which can be respectively obtained from the ordinate and slope of the double logarithmic regression curve of $\log \left[\left(F_{0^{-}} F\right) / F\right]$ vs. $\log$ [Q] based on the equation.

ELISA analysis. The binding activity of AD5 to cyclin D1 was evaluated using an ELISA, according to a previous study (13). A total of $100 \mu \mathrm{l}$ purified human recombinant cyclin D1 $(10 \mu \mathrm{g} / \mathrm{ml})$ was coated onto the surface of wells in a 96-well microtiter plate (Thermo Fisher Scientific, Inc., Waltham, MA, USA) overnight at $4^{\circ} \mathrm{C}$. Non-specific binding sites were blocked with $0.05 \%$ Tween-20 in PBS (PBST) containing $5 \%$ non-fat milk for $1 \mathrm{~h}$ at room temperature. The wells were incubated with $100 \mu$ l AD5 treated with $\mathrm{Cu}^{2+}$ or $\mathrm{Fe}^{3+}$ (at the same concentration as the above fluorescence spectra analysis) for $2 \mathrm{~h}$ at $37^{\circ} \mathrm{C}$. Following 3 washes with PBST, anti-V5-tag antibody (1:5,000 dilution in PBST containing 3\% non-fat milk) were added to each well and incubated for $2 \mathrm{~h}$ at $37^{\circ} \mathrm{C}$. The plate was washed with PBST followed by incubation with HRP-conjugated goat anti-mouse IgG (1:5,000 dilution in PBST containing $3 \%$ non-fat milk) for $1 \mathrm{~h}$ at $37^{\circ} \mathrm{C}$. The reaction was developed by adding $200 \mu \mathrm{l}$ OPD substrate $(1 \mathrm{mg} / \mathrm{ml}$ in citrate-phosphate buffer with $0.02 \%$ hydrogen peroxide) and the absorbance was measured using a microplate reader (Thermo Labsystems, Santa Rosa, CA, USA) at a wavelength of $492 \mathrm{~nm}$. Microplates were incubated with the equal volume of BSA instead of cyclin D1 as a negative control.

Statistical analysis. Experiments were performed in triplicate and the reported values are representative of three independent experiments. Data are expressed as the mean \pm standard deviation of three parallel measurements within the same experiment. Comparisons among multiple groups were analyzed by one-way analysis of variance with a Bonferroni post hoc test. Statistical analysis was performed using GraphPad Prism software (version 5.0; GraphPad Software Inc., La Jolla, CA, USA). $\mathrm{P}<0.05$ was considered to indicate a statistically significant difference.

\section{Results}

$\mathrm{Cu}^{2+}$ and $\mathrm{Fe}^{3+}$ induce the fluorescence quenching of AD5. Fluorescence spectroscopy is considered to be a comprehensive method for determining protein-ligand interactions. In the present study, fluorescence spectroscopy was utilized to investigate the interaction between AD5 and $\mathrm{Cu}^{2+}$ or $\mathrm{Fe}^{3+}$. When small molecules interact with AD5, the intrinsic fluorescence fluorophores (Trp, Tyr and Phe) may be altered depending on the impact of such interaction on the protein conformation $(24,25)$. As demonstrated in Fig. 1, as the metal 
ion concentration increased, the fluorescence intensity of AD5 markedly decreased at temperatures of 293, 298 and $303 \mathrm{~K}$. Therefore, $\mathrm{Cu}^{2+}$ and $\mathrm{Fe}^{3+}$ quench the fluorescence intensity of AD5 at different temperatures, and may alter the microenvironment and conformation of AD5.

Quenching mechanism analysis. The two types of fluorescence quenching mechanisms, including the dynamic quenching mechanism and the static quenching mechanism, differ depending on temperature. The dynamic quenching constant increases as the temperature rises, while the static quenching constant is reduced accordingly. To verify the quenching mechanism of $\mathrm{Cu}^{2+}$-AD5 and $\mathrm{Fe}^{3+}-\mathrm{AD} 5$ complexes, the fluorescence intensities in the absence or presence of a quencher $\left(F_{0} / F\right)$ was plotted against the concentration of $\mathrm{Cu}^{2+}$ or $\mathrm{Fe}^{3+}$ (Fig. 2).

The results deduced by the Stern-Volmer equation are shown in Table I. The standard deviation provides a measure of how much the observed values differ from the values provided by the regression line. A low standard deviation indicates that the data points were similar to the values obtained from the regression line. For dynamic quenching, the maximum $K_{\mathrm{q}}$ of various quenchers with a biopolymer is $2.00 \times 10^{10} \mathrm{M}^{-1}$ $\mathrm{s}^{-1}(26)$. As these $K_{\mathrm{q}}$ values are markedly greater than the maximum collisional quenching constant $\left(2.00 \times 10^{10} \mathrm{M}^{-1} \mathrm{~s}^{-1}\right)$, it was concluded that the static quenching mechanism served a dominant role in the $\mathrm{Cu}^{2+}-\mathrm{AD} 5$ and $\mathrm{Fe}^{3+}$-AD5 interaction (26).

Evaluation of the binding constant $\left(K_{b}\right)$ and the number ofbinding sites. For the static quenching, the number of binding sites for one AD5 molecule can be respectively obtained from the ordinate and slope of the double logarithmic regression curve (Fig. 3) of $\log \left[\left(F_{0}-F\right) / F\right]$ vs. $\log [\mathrm{Q}]$ based on the equation. The number of binding sites and $K_{\mathrm{b}}$ values were calculated and presented in Table II. The number of binding sites (n) was approximately 1 , indicating that there was one binding site in $\mathrm{AD} 5$ for $\mathrm{Cu}^{2+}$ or $\mathrm{Fe}^{3+}$ (Table II). In addition, $K_{\mathrm{b}}$ values calculated for the $\mathrm{Fe}^{3+}-\mathrm{AD} 5$ and $\mathrm{Cu}^{2+}-\mathrm{AD} 5$ system suggested that the $\mathrm{Fe}^{3+}-\mathrm{AD} 5$ system binding affinity increased with increasing temperature, whereas $\mathrm{Cu}^{2+}$-AD5 system binding affinity was greatest at $298 \mathrm{~K}$ (Table II).

Analysis of AD5 conformational alterations. Synchronous fluorescence spectroscopy is used to analyze the microenvironment of amino acid residues and to evaluate protein conformation by measurement of the emission wavelength shift, as the maximum emission wavelength of Trp or Tyr residues is associated with the polarity of their environment (27-29). The synchronous fluorescence spectra exhibit the spectral character of Tyr and Trp residues when the $\Delta \lambda$ is 15 and $60 \mathrm{~nm}$, respectively (27).

The synchronous fluorescence spectra of AD5 upon the addition of $\mathrm{Cu}^{2+}$ or $\mathrm{Fe}^{3+}$ at $\Delta \lambda=60 \mathrm{~nm}$ and $\Delta \lambda=15 \mathrm{~nm}$ are indicated in Fig. 4. The quenching of the fluorescence intensity with $\mathrm{Cu}^{2+}$ was stronger when compared with $\mathrm{Fe}^{3+}$, suggesting that $\mathrm{Cu}^{2+}$ contributes to the quenching of the intrinsic fluorescence of AD5 to a greater extent than $\mathrm{Fe}^{3+}$.

Effect of $\mathrm{Cu}^{2+}$ and $\mathrm{Fe}^{3+}$ on the biological activity of AD5. To verify the effects of metal ions on the biological activity of
Table I. Stern-Volmer $K_{\mathrm{sv}}$ and $K_{\mathrm{q}}$ of the $\mathrm{Cu}^{2+} / \mathrm{Fe}^{3+}-\mathrm{AD} 5$ interaction system.

$\mathrm{A}, \mathrm{Cu}^{2+}-\mathrm{AD} 5$

\begin{tabular}{lllll}
\hline $\mathrm{T}(K)$ & $K_{\mathrm{sv}}\left(\mathrm{M}^{-1}\right)$ & $K_{\mathrm{q}}\left(\mathrm{M}^{-1} \mathrm{~s}^{-1}\right)$ & $\mathrm{R}$ & $\mathrm{SD}$ \\
\hline 293 & $1.98 \times 10^{3}$ & $1.98 \times 10^{11}$ & 0.978 & 0.133 \\
298 & $2.38 \times 10^{3}$ & $2.38 \times 10^{11}$ & 0.996 & 0.069 \\
303 & $2.96 \times 10^{3}$ & $2.96 \times 10^{11}$ & 0.973 & 0.218 \\
\hline
\end{tabular}

$\mathrm{B}, \mathrm{Fe}^{3+}-\mathrm{AD} 5$

\begin{tabular}{lllll}
\hline $\mathrm{T}(K)$ & $K_{\mathrm{sv}}\left(\mathrm{M}^{-1}\right)$ & $K_{\mathrm{q}}\left(\mathrm{M}^{-1} \mathrm{~s}^{-1}\right)$ & $\mathrm{R}$ & $\mathrm{SD}$ \\
\hline 293 & $6.54 \times 10^{5}$ & $6.54 \times 10^{13}$ & 0.996 & 0.196 \\
298 & $6.56 \times 10^{5}$ & $6.56 \times 10^{13}$ & 0.993 & 0.240 \\
303 & $9.44 \times 10^{5}$ & $9.43 \times 10^{13}$ & 0.973 & 0.697
\end{tabular}

The experimental conditions were as follows: $\mathrm{pH} 7.4 ; \lambda \mathrm{ex}, 280 \mathrm{~nm}$;

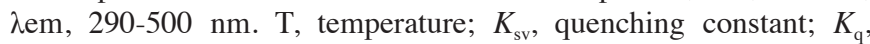
bimolecular quenching rate constant; R, linear correlated coefficient; $\mathrm{SD}$, standard deviation; AD5, anti-cyclin D1 single-chain variable fragment.

Table II. $K_{\mathrm{b}}$ and the number of binding sites of the $\mathrm{Cu}^{2+}-\mathrm{AD} 5$ or $\mathrm{Fe}^{3+}-\mathrm{AD} 5$ interaction at different temperatures.

\begin{tabular}{lcccc}
\hline $\mathrm{A}, \mathrm{Cu}^{2+}-\mathrm{AD} 5$ & & & & \\
\hline $\mathrm{T}(K)$ & $K_{\mathrm{b}}\left(\mathrm{M}^{-1}\right)$ & $\mathrm{n}$ & $\mathrm{R}$ & $\mathrm{SD}$ \\
\hline 293 & 95.504 & 1.776 & 0.988 & 0.025 \\
298 & 110.943 & 1.276 & 0.964 & 0.031 \\
303 & 104.002 & 1.243 & 0.963 & 0.031 \\
\hline $\mathrm{B}, \mathrm{Fe}^{3+}-\mathrm{AD} 5$ & & & & \\
\hline $\mathrm{T}(K)$ & & & & \\
\hline 293 & $K_{\mathrm{b}}\left(\mathrm{M}^{-1}\right)$ & $\mathrm{n}$ & $\mathrm{R}$ & $\mathrm{SD}$ \\
298 & 61.916 & 1.102 & 0.995 & 0.010 \\
303 & 64.055 & 1.053 & 0.992 & 0.012 \\
\hline
\end{tabular}

The $\mathrm{pH}$ of both systems was 7.4. T, temperature; $K_{\mathrm{b}}$, binding constant; $\mathrm{n}$, number of binding sites; $\mathrm{R}$, linear correlated coefficient; SD, standard deviation; AD5, anti-cyclin D1 single-chain variable fragment.

AD5, ELISA assays were performed with various concentrations of $\mathrm{Cu}^{2+}$ or $\mathrm{Fe}^{3+}$ at room temperature $(298 \mathrm{~K})$. As demonstrated in Fig. 5, the effects of $\mathrm{Cu}^{2+}$ on the binding activity of AD5 to cyclin D1 was different from that of $\mathrm{Fe}^{3+}$. Although low concentrations of $\mathrm{Cu}^{2+}$ reduced the binding activity of AD5 to cyclin D1 and relatively high concentrations of $\mathrm{Cu}^{2+}$ enhanced the binding activity of AD5 to cyclin D1, the results did not reach statistical significance when 

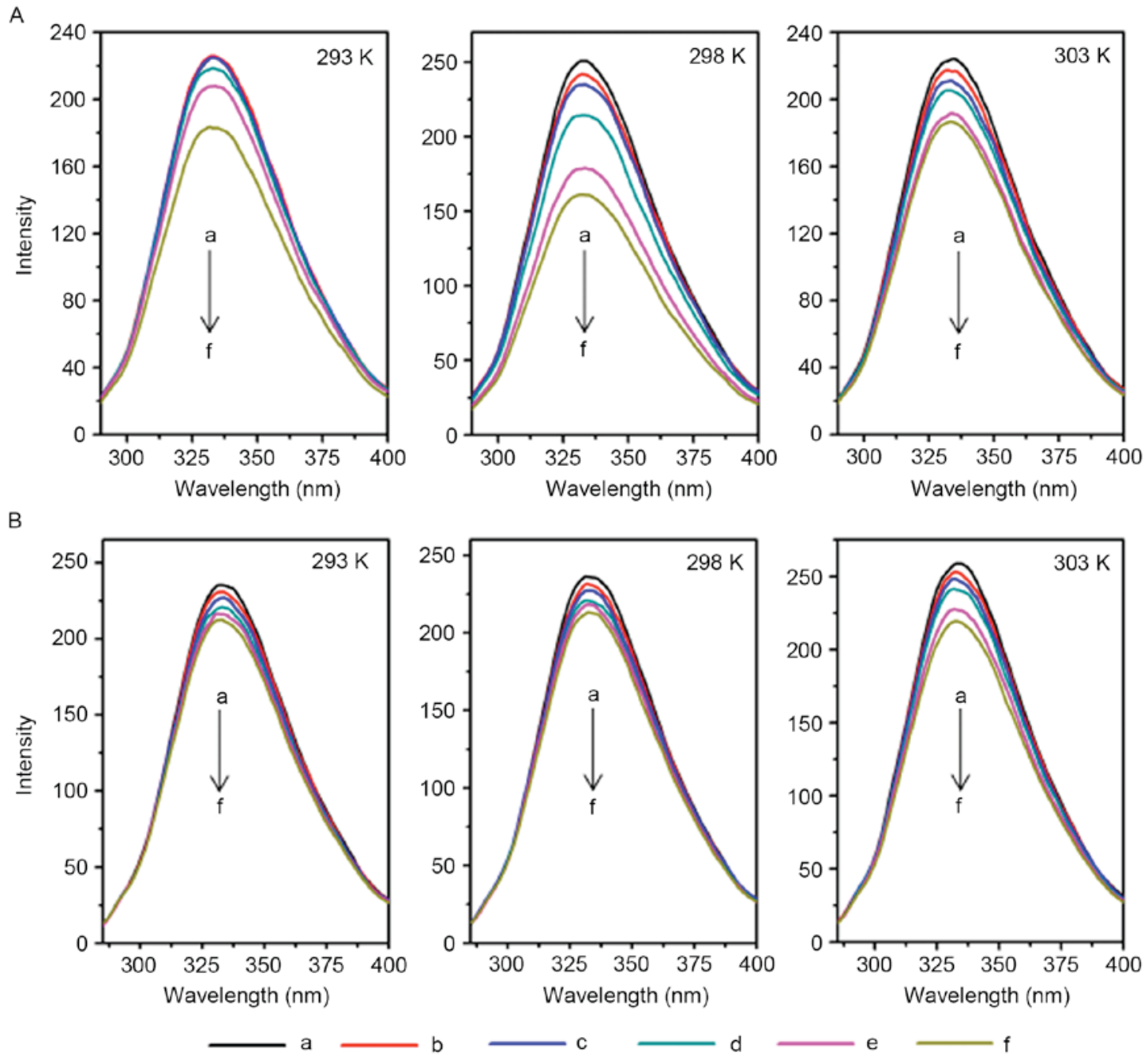

Figure 1. Fluorescence spectra of AD5 treated with various concentrations of $\mathrm{Cu}^{2+}$ or $\mathrm{Fe}^{3+}$. AD5 $\left(2 \times 10^{-6} \mathrm{M}\right)$ was treated with various concentrations of (A) $\mathrm{Cu}^{2+}$ or (B) $\mathrm{Fe}^{3+}$, and the fluorescence spectra assay was performed. The $\lambda$ ex and $\lambda$ em were $280 \mathrm{~nm}$ and $290-500 \mathrm{~nm}$, respectively (pH 7.4). a, $0.00 \times 10^{-3} \mathrm{M}$; b, $0.33 \times 10^{-3} \mathrm{M} ; \mathrm{c}, 0.67 \times 10^{-3} \mathrm{M} ; \mathrm{d}, 1.00 \times 10^{-3} \mathrm{M} ; \mathrm{e}, 1.33 \times 10^{-3} \mathrm{M} ; \mathrm{f}, 1.67 \times 10^{-3} \mathrm{M}$; AD5, anti-cyclin D1 single-chain variable fragment; $\lambda$ ex, excitation wavelength; $\lambda$ em, emission wavelength.

compared with $0.00 \mathrm{M} \mathrm{Cu}^{2+}$ treatment (Fig. 5). However, the absorbance at $492 \mathrm{~nm}$ was significantly reduced following $\mathrm{Fe}^{3+}$ treatment when compared with the $0.00 \mathrm{M} \mathrm{Fe}^{3+}$-treated control group $\left(\mathrm{P}<0.05\right.$; Fig. 5). This suggested that $\mathrm{Fe}^{3+}$ reduced the binding activity of AD5 to cyclin D1 and inhibited the biological activity of AD5.

\section{Discussion}

Cyclin D1 is the regulatory subunit of a holoenzyme that phosphorylates and inactivates the retinoblastoma protein and promotes progression through the $G_{1}-S$ phase of the cell cycle $(1,2)$. Amplification or overexpression of cyclin D1 serves a role in the development of a subset of human cancers, including melanoma and breast, colon and prostate cancer (30). Overexpression of cyclin D1 may lead to aberrant cell growth, proliferation and tumorigenesis (31). Cyclin D1 has become a potential prognostic marker and a therapeutic target for cancer $(4,32,33)$. The scFv may be useful for cancer prevention, diagnosis and therapy due to its specific binding affinity to its antigens, its small size, and ease of engineering to include modifications, such as the production of intrabodies $(9,10,12,34)$. In a previous study, a novel human AD5 scFv with specific binding affinity to cyclin D1 was designed (13), and an intracellular anti-cyclin D1 scFv suppressed the growth and proliferation of HeLa and MCF-7 cells $(14,15)$. Investigations using intracellular AD5 have suggested that $\mathrm{scFv}$ may be a powerful tool to inhibit the function of cyclin D1 in cancer cells $(14,15)$. However, the mechanism of action and biological characteristics of AD5 remain to be understood. In the present study, the effects of metal ions on the structure and activity of AD5 were investigated by spectroscopy analysis and ELISA. The results revealed that the fluorescence of AD5 may be quenched by $\mathrm{Cu}^{2+}$ and $\mathrm{Fe}^{3+}$. Quenching mechanism analysis demonstrated that static quenching was dominant in the AD5-metal ion system. In addition, the effects of $\mathrm{Fe}^{3+}$ on AD5 activity were stronger than that of $\mathrm{Cu}^{2+}$. The ELISA results revealed that $\mathrm{Cu}^{2+}$ and $\mathrm{Fe}^{3+}$ demonstrated different effects on the biological activity of AD5, where $\mathrm{Cu}^{2+}$ had few effects on AD5 activity, whereas $\mathrm{Fe}^{3+}$ significantly reduced the biological activity of AD5 binding to cyclin D1. These results may facilitate an improved understanding of the characteristics of AD5. 
A

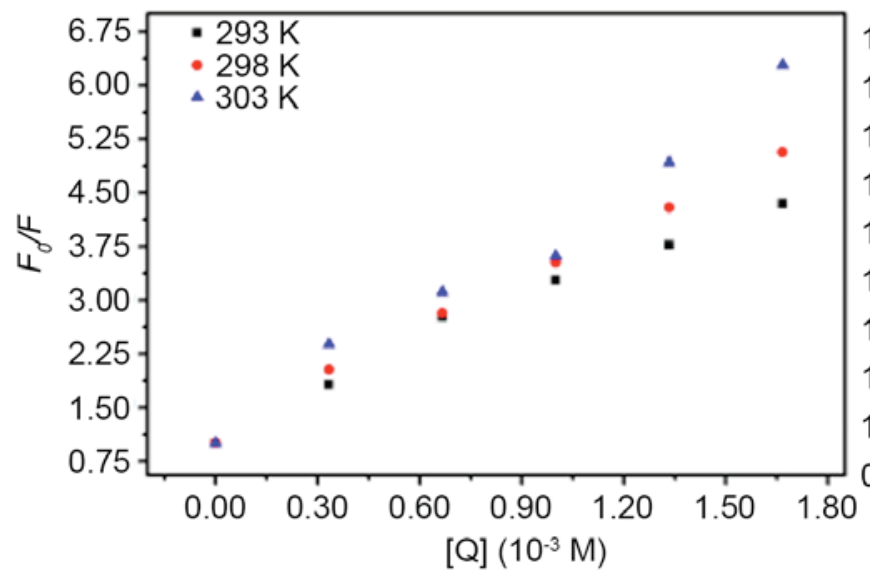

$\mathrm{B}$

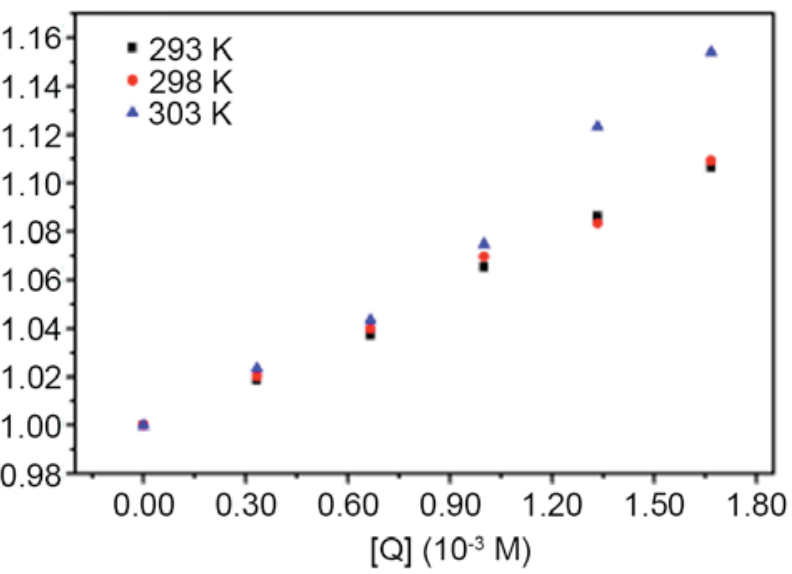

Figure 2. Stern-Volmer plots of AD5 quenching by (A) $\mathrm{Cu}^{2+}$ and (B) $\mathrm{Fe}^{3+}$ at temperatures of 293, 298 and $303 \mathrm{~K}$. The concentration of $\mathrm{AD} 5$ was $2 \times 10^{-6} \mathrm{M}$ and the $\mathrm{Cu}^{2+}$ and $\mathrm{Fe}^{3+}$ concentrations were $0.00,0.33,0.67,1.00,1.33$ and $1.67 \times 10^{-3} \mathrm{M}$, respectively. The $\lambda$ ex and $\lambda$ em were $280 \mathrm{~nm}$ and $290-500 \mathrm{~nm}$, respectively $\left(\mathrm{pH}\right.$ 7.4). AD5, anti-cyclin D1 single-chain variable fragment; $\lambda$ ex, excitation wavelength; $\lambda \mathrm{em}$, emission wavelength; $F_{0}$, fluorescence intensity in the absence of a quencher; $F$, fluorescence intensity in the presence of a quencher; [Q], concentration of quencher.

A

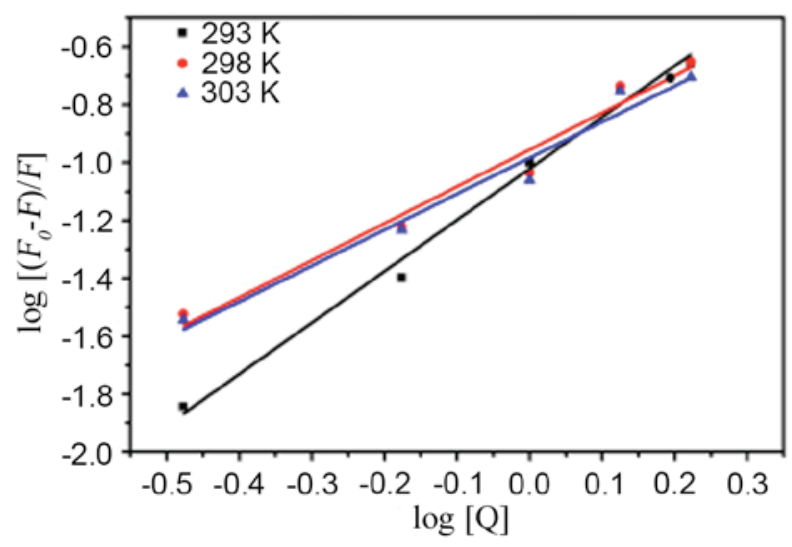

B

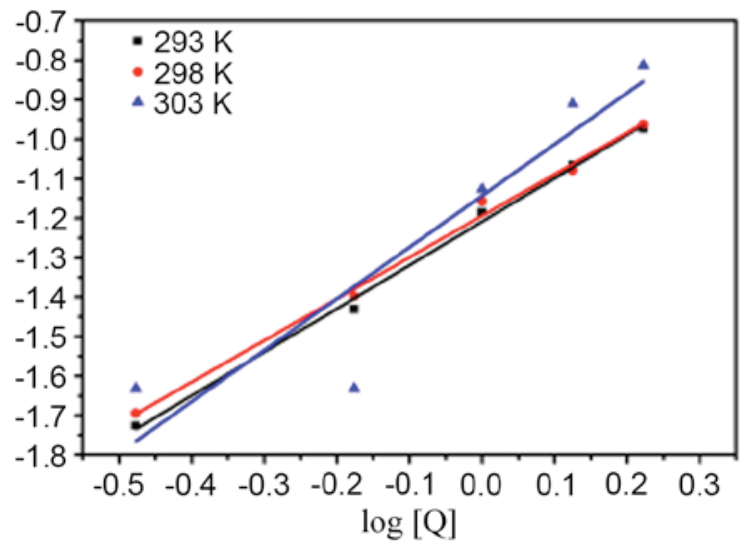

Figure 3. Quenching effects of $\mathrm{Cu}^{2+}$ or $\mathrm{Fe}^{3+}$ on AD5 fluorescence at different temperatures. (A) $\mathrm{Cu}^{2+}-\mathrm{AD} 5$ system and (B) $\mathrm{Fe}^{3+}-\mathrm{AD} 5$ system at temperatures of 293,298 and $303 \mathrm{~K}$. The concentration of AD5 was $2 \times 10^{-6} \mathrm{M}$, and the $\mathrm{Cu}^{2+}$ and $\mathrm{Fe}^{3+}$ concentrations were $0.00,0.33,0.67,1.00,1.33$ and $1.67 \times 10^{-3} \mathrm{M}$. The $\lambda$ ex and $\lambda$ em were $280 \mathrm{~nm}$ and $290-500 \mathrm{~nm}$, respectively (pH 7.4). AD5, anti-cyclin D1 single-chain variable fragment; $\lambda$ ex, excitation wavelength; $\lambda$ em, emission wavelength; $F_{0}$, fluorescence intensity in the absence of a quencher; $F$, fluorescence intensity in the presence of a quencher; [Q], concentration of quencher.

Spectroscopy is the favored method in the study of functional protein structure, including scFvs. Jäger and Plückthun (35) compared the equilibrium denaturation and unfolding kinetics of the variable domain light chain $(\mathrm{VL})$ and variable domain heavy chains $(\mathrm{VH})$ with those of the fragment variable $(\mathrm{Fv})$ and $\mathrm{scFv}$ of an engineered variant of the McPC603 antibody, in the presence and absence of the phosphorylcholine antigen by fluorescence spectroscopy. The results demonstrated that scFv fragment is significantly more stable than the isolated constitutive domains. Paoletti et al (36) revealed that, in response to an excitation wavelength of $295 \mathrm{~nm}$, the maximum fluorescence of native anti-nerve growth factor precursor $\mathrm{scFv}$ was $334 \mathrm{~nm}$, whereas in denaturing conditions, the fluorescence maximum was shifted towards higher wavelengths of $353 \mathrm{~nm}$ (36). In the present study, the structural alterations of AD5 in the presence of metal ions were investigated by spectroscopy. The results demonstrated that AD5 fluorescence was quenched by $\mathrm{Cu}^{2+}$ or $\mathrm{Fe}^{3+}$. Synchronous fluorescence revealed that the AD5 chromophore environment was altered slightly in the presence of $\mathrm{Cu}^{2+}$ or $\mathrm{Fe}^{3+}$, leading to polarity, hydrophobicity and a minor alteration of AD5 conformation. The findings of the present study suggested that each AD5 molecule possessed $\sim 1 \mathrm{Cu}^{2+}$ or $\mathrm{Fe}^{3+}$ binding site. This may provide additional information regarding the spectroscopy characteristics of scFv.

The binding activity of an antibody to its antigen is critical in determining its function. In a previous study, the active anti-cyclin D1 single chain antibody, AD5, was designed. This antibody binds specifically to human recombinant cyclin D1 with a moderate affinity constant (13). However, increasing evidence suggests that antibodies with moderate affinity $\left(10^{-7}-10^{-9} \mathrm{M}\right)$ may facilitate effective penetration into tumors and to enhance anti-tumor activities in cancer cells (37-39). In addition, low binding activity may result in inefficient therapy (8). The results of the present study revealed that $\mathrm{Fe}^{3+}$ disturbed the binding between AD5 and cyclin D1. The biological activity of AD5 was significantly reduced by $\mathrm{Fe}^{3+}$. 

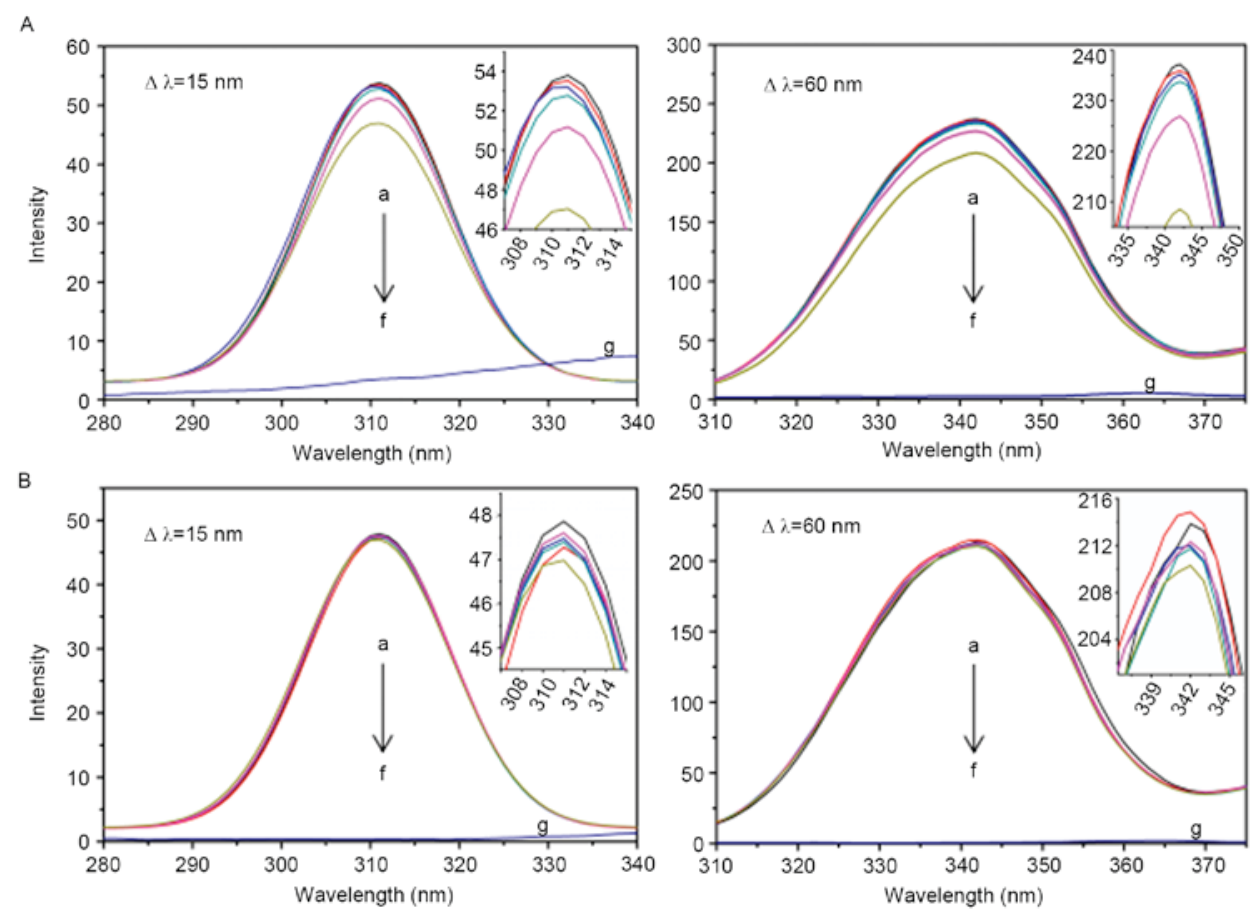

Figure 4. Synchronous fluorescence spectra of AD5 treated with various concentrations of $\mathrm{Cu}^{2+}$ or Fe $^{3+}$. AD5 $\left(2 \times 10^{-6} \mathrm{M}\right)$ was treated with various concentrations of $\mathrm{Cu}^{2+}$ or $\mathrm{Fe}^{3+}$, and a synchronous fluorescence spectra assay was performed at $\Delta \lambda=15 \mathrm{~nm}$ and $\Delta \lambda=60 \mathrm{~nm}$ and at a temperature of $298 \mathrm{~K}$ ( $\mathrm{pH} 7.4$ ). Synchronous fluorescence spectra of AD5 treated with various concentrations of (A) $\mathrm{Cu}^{2+}$ at $\Delta \lambda=15 \mathrm{~nm}$ (left panel) and $\Delta \lambda=60 \mathrm{~nm}$ (right panel) or (B) Fe ${ }^{3+}$ at $\Delta \lambda=15 \mathrm{~nm}$ (left panel) and $\Delta \lambda=60 \mathrm{~nm}$ (right panel). A partially enlarged view of the peak in the synchronous emission spectra is included in the top right corner of every figure. a, $0.00 \times 10^{-3} \mathrm{M} ; \mathrm{b}, 0.33 \times 10^{-3} \mathrm{M} ; \mathrm{c}, 0.67 \times 10^{-3} \mathrm{M} ; \mathrm{d}, 1.00 \times 10^{-3} \mathrm{M}$; e, $1.33 \times 10^{-3} \mathrm{M} ; \mathrm{f}, 1.67 \times 10^{-3} \mathrm{M}$; AD5, anti-cyclin D1 single-chain variable fragment; $\Delta \lambda$, wavelength interval.
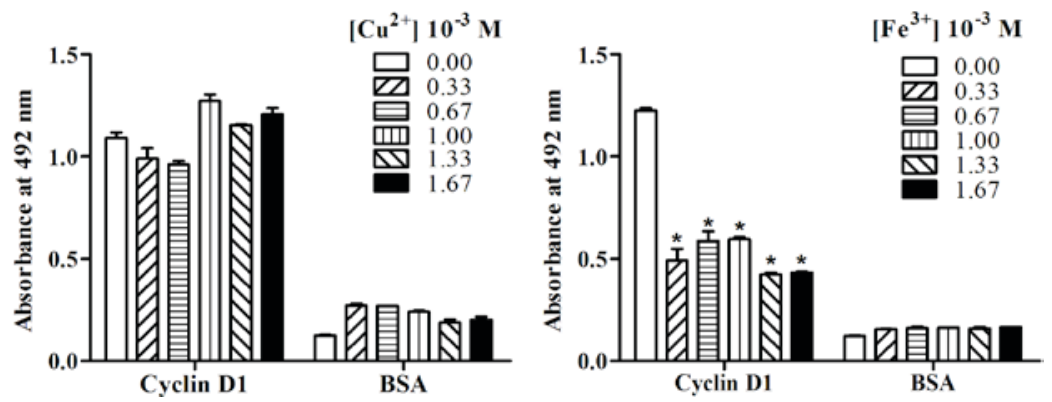

Figure 5. Effects of $\mathrm{Cu}^{2+}$ and $\mathrm{Fe}^{3+}$ on the binding activity of AD5 to cyclin D1. Wells were coated with BSA or AD5 and treated with 0.00, 0.33, 0.67, 1.00, 1.33 and $1.67 \times 10^{-3} \mathrm{M} \mathrm{Cu}^{2+}$ or $\mathrm{Fe}^{3+}$. An enzyme-linked immunosorbent assay was performed and the absorbance was measured at $492 \mathrm{~nm}$. Data are expressed as the mean \pm standard deviation of three replicates in the same experiment. ${ }^{*}<0.05$ vs. AD5 treated with $0.00 \mathrm{M}$ Fe ${ }^{3+}$. AD5, anti-cyclin D1 single-chain variable fragment; BSA, bovine serum albumin.

However, $\mathrm{Cu}^{2+}$ had few effects on the binding activity of AD5 to cyclin D1. These results may facilitate the identification of optimal working conditions of AD5 for tumor therapy or cyclin D1 detection. The specific association between antibodies and antigens is primarily based on the interactions between the epitope of the antigen and complementary determinant regions in the VH/VL domain of the antibody molecule $(40,41)$. Therefore, a strong antigen-antibody interaction depends on a close structural fit between antigen and antibody. Therefore, these interactions may occur if the antigen and antibody have precise conformations and are in close proximity $(41,42)$. The results of the present study suggested that $\mathrm{Cu}^{2+}$ and $\mathrm{Fe}^{3+}$ demonstrate similar effects on $\mathrm{AD} 5$ conformation, as $\mathrm{Cu}^{2+}$ or $\mathrm{Fe}^{3+}$ induced slight AD5 conformation alterations. Therefore, the underlying reason why $\mathrm{Fe}^{3+}$ significantly inhibited the biological activity of AD5 is not explained by the $\mathrm{Fe}^{3+}$-induced conformational alterations. However, it is likely that $\mathrm{Fe}^{3+}$ inhibits the interaction between AD5 and cyclin D1 via association with key amino acids of AD5 involved in binding to cyclin D1. Further investigation to elucidate the underlying mechanisms for the stronger effects of $\mathrm{Fe}^{3+}$ on AD5 activity than $\mathrm{Cu}^{2+}$ is warranted.

In conclusion, the results of the present study provide important information regarding the structure and biological activity of AD5 and how it is affected by metal ions. This may provide a foundation for elucidating the mechanism of action of AD5 and its potential clinical applications. 


\section{Acknowledgements}

The present study was partially supported by the National Natural Science Foundation of China (grant nos. 31170882 and 31570934), the S\&T Development Planning Program of Jilin Province (grant nos. 20111806, 20150414027GH and 20160101213JC) and the Fundamental Research Funds for the Central Universities (grant nos. 451160306023 and JCKY-QKJC-01).

\section{References}

1. Casimiro MC, Velasco-Velázquez M, Aguirre-Alvarado C and Pestell RG: Overview of cyclin D1 function in cancer and the CDK inhibitor landscape: Past and present. Expert Opin Investig Drugs 23: 295-304, 2014.

2. Choi YJ, Li X, Hydbring P, Sanda T, Stefano J, Christie AL, Signoretti S, Look AT, Kung AL, von Boehmer H and Sicinski P: The requirement for cyclin $\mathrm{D}$ function in tumor maintenance. Cancer Cell 22: 438-451, 2012.

3. Beroukhim R, Mermel CH, Porter D, Wei G, Raychaudhuri S, Donovan J, Barretina J, Boehm JS, Dobson J, Urashima M, et al: The landscape of somatic copy-number alteration across human cancers. Nature 463: 899-905, 2010

4. Musgrove EA, Caldon CE, Barraclough J, Stone A and Sutherland RL: Cyclin D as a therapeutic target in cancer. Nat Rev Cancer 11: 558-572, 2011.

5. Casimiro MC, Crosariol M, Loro E, Li Z and Pestell RG: Cyclins and cell cycle control in cancer and disease. Genes Cancer 3 : 649-657, 2012.

6. Roy PG, Pratt N, Purdie CA, Baker L, Ashfield A, Quinlan P and Thompson AM: High CCND1 amplification identifies a group of poor prognosis women with estrogen receptor positive breast cancer. Int J Cancer 127: 355-360, 2010

7. Alao JP: The regulation of cyclin D1 degradation: Roles in cancer development and the potential for therapeutic invention. Mol Cancer 6: 24, 2007.

8. Ahmad ZA, Yeap SK, Ali AM, Ho WY, Alitheen NB and Hamid M: scFv antibody: Principles and clinical application. Clin Dev Immunol 2012: 980250, 2012.

9. Scott AM, Wolchok JD and Old LJ: Antibody therapy of cancer. Nat Rev Cancer 12: 278-287, 2012.

10. Elvin JG, Couston RG and van der Walle CF: Therapeutic antibodies: Market considerations, disease targets and bioprocessing. Int J Pharm 440: 83-98, 2013.

11. Holliger P and Hudson PJ: Engineered antibody fragments and the rise of single domains. Nat Biotechnol 23: 1126-1136, 2005.

12. Weisser NE and Hall JC: Applications of single-chain variable fragment antibodies in therapeutics and diagnostics. Biotechnol Adv 27: 502-520, 2009.

13. Wu Y, Zou D, Cao Y, Yao N, Wang J, Wang W, Jiang H and Li GY: Expression and purification of a human anti-cyclin D1 single-chain variable fragment antibody AD5 and its characterization. Int J Mol Med 32: 1451-1457, 2013.

14. Zhou LH, Zhu X, Cao YH, Wang L, Chen Y, Du Br and Li GY: Construction of expression vector for anti-cyclin D1 intrabody AD5N and its inhibitory effects on cell proliferation of breast cancer. Chin J Immunol 24: 703-706, 2008.

15. Zhou LH, Zhu X, Cao YH, Chen Y, Tian Y, Wang L and Li GY: Effects of anti-cyclin D1 intrabody AD5N on HeLa cells of uterine cervix cancer. Chin J Clin Oncol 35: 942-944, 2008.

16. Avanti C, Oktaviani NA, Hinrichs WL, Frijlink HW and Mulder FA: Aspartate buffer and divalent metal ions affect oxytocin in aqueous solution and protect it from degradation. Int J Pharm 444: 139-145, 2013.

17. Tainer JA, Roberts VA and Getzoff ED: Protein metal-binding sites. Curr Opin Biotechnol 3: 378-387, 1992.

18. Trisler K, Looger LL, Sharma V, Baker M, Benson DE, Trauger S, Schultz PG and Smider VV: A metalloantibody that irreversibly binds a protein antigen. J Biol Chem 282: 26344-26353, 2007.

19. Iverson BL, Iverson SA, Roberts VA, Getzoff ED, Tainer JA, Benkovic SJ and Lerner RA: Metalloantibodies. Science 249: $659-662,1990$
20. Zhang YP, Shi SY, Huang KL, Chen XQ and Peng MJ: Effect of $\mathrm{Cu}^{2+}$ and $\mathrm{Fe}^{3+}$ for drug delivery: Decreased binding affinity of ilaprazole to bovine serum albumin. J Lumin 131: 1927-1931, 2011.

21. Li GY, Zou DS and Zhou LH: Expression and purification of recombinant human cyclin D1 in E. coli BL21. J Jilin Univ 44: 839-843, 2006.

22. Lakowicz JR (ed): Principles of Fluorescence Spectroscopy. Plenum Press, New York, NY, pp260-266, 1983.

23. Bian H, Li M, Yu Q, Chen Z, Tian J and Liang Q: Study of the interaction of artemisinin with bovine serum albumin. Int J Biol Macromol 39: 291-297, 2006.

24. Liu Y, Chen M, Bian G, Liu J and Song L: Spectroscopic investigation of the interaction of the toxicant, 2-naphthylamine, with bovine serum albumin. J Biochem Mol Toxicol 25: 362-368, 2011.

25. Zhao X, Sheng F, Zheng J and Liu R: Composition and stability of anthocyanins from purple solanum tuberosum and their protective influence on $\mathrm{Cr}(\mathrm{VI})$ targeted to bovine serum albumin. J Agric Food Chem 59: 7902-7909, 2011.

26. Lu D, Zhao X, Zhao Y, Zhang B, Zhang B, Geng M and Liu R: Binding of Sudan II and Sudan IV to bovine serum albumin: Comparison studies. Food Chem Toxicol 49: 3158-3164, 2011.

27. Miller JN: Recent advances in molecular luminescence analysis. Proc Anal Div Chem Soc 16: 203-208, 1979.

28. Ye ZW, Ying Y, Yang XL, Zheng ZQ, Shi JN, Sun YF and Huang P: A spectroscopic study on the interaction between the anticancer drug erlotinib and human serum albumin. J Incl Phenom Macrocycl Chem 78: 405-413, 2014.

29. Cao X, Dong D, Liu J, Jia C, Liu W and Yang W: Studies on the interaction between triphenyltin and bovine serum albumin by fluorescence and CD spectroscopy. Chemosphere: 26 Jan, 2013 [Epub ahead of Print].

30. Fu M, Wang C, Li Z, Sakamaki T and Pestell RG: Minireview: Cyclin D1: Normal and abnormal functions. Endocrinology 145: 5439-5447, 2004.

31. Neumeister P, Pixley FJ, Xiong Y, Xie H, Wu K, Ashton A, Cammer M, Chan A, Symons M, Stanley ER and Pestell RG: Cyclin D1 governs adhesion and motility of macrophages. Mol Biol Cell 14: 2005-2015, 2003.

32. Malumbres M: Cell cycle-based therapies move forward. Cancer Cell 22: 419-420, 2012.

33. Ding Z, Wu CJ, Chu GC, Xiao Y, Ho D, Zhang J, Perry SR, Labrot ES, Wu X, Lis R, et al: SMAD4-dependent barrier constrains prostate cancer growth and metastatic progression. Nature 470: 269-273, 2011.

34. Dai H, Gao H, Zhao X, Dai L, Zhang X, Xiao N, Zhao R and Hemmingsen SM: Construction and characterization of a novel recombinant single-chain variable fragment antibody against white spot syndrome virus from shrimp. J Immunol Methods 279: 267-275, 2003.

35. Jäger M and Plückthun A: Domain interactions in antibody Fv and scFv fragments: Effects on unfolding kinetics and equilibria. FEBS Lett 462: 307-312, 1999.

36. Paoletti F, Malerba F, Konarev PV, Visintin M, Scardigli R, Fasulo L, Lamba D, Svergun DI and Cattaneo A: Direct intracellular selection and biochemical characterization of a recombinant anti-proNGF single chain antibody fragment. Arch Biochem Biophys 522: 26-36, 2012.

37. Adams GP and Schier R: Generating improved single-chain Fv molecules for tumor targeting. J Immunol Methods 231: 249-260, 1999.

38. Adams GP, Schier R, Marshall K, Wolf EJ, McCall AM, Marks JD and Weiner LM: Increased affinity leads to improved selective tumor delivery of single-chain Fv antibodies. Cancer Res 58: 485-490, 1998.

39. Adams GP, Schier R, McCall AM, Simmons H, Horak E, Marks JD and Weiner LM: What are the determinants of antibody-based targeting? Proc Amer Assoc Cancer Res 39: 436, 1998.

40. Sela-Culang I, Kunik V and Ofran Y: The structural basis of antibody-antigen recognition. Front Immunol 4: 302, 2013.

41. Goldsby RA, Kindt TJ, Kuby J and Osborne BA: Immunology 5th Edition, W. H. Freeman and Company Publishers, New York, 2003.

42. Burkovitz A, Leiderman O, Sela-Culang I, Byk G and Ofran Y: Computational identification of antigen-binding antibody fragments. J Immunol 190: 2327-2334, 2013. 